\title{
Intellectual property rights of nano-biotechnology in trade related aspects of intellectual property agreement
} (TRIPS)

\author{
Abutaleb Koosha, Maryam Ahmadi ${ }^{*}$, Abbas Nazifi and Reza Mousazadeh \\ Department of Life Science, Payam e Noor University of Tehran, Tehran, Iran \\ *mrmahmadi41@gmail.com
}

\begin{abstract}
The emergent field of nanobiotechnology is currently very active worldwide with respect to intellectual property rights (IPR), especially patents. With the emergence of any new technology, nanobiotechnology creates opportunities as well as challenges in adapting the patent regime to its particular context. There is some consensus that patenting nanobiotechnology innovations poses problems than other technologies, owing to their multi-disciplinary character, cross-sectoral applications, broad claims, as well as difficulties in fulfilling the patentability criteria of novelty, nonobviousness, and industrial application. This is aggravated by the lack of a standardized terminology, which impedes easy identification of nanobio patents and the fact that patent offices may not be well equipped to handle nanobiotechnology. This paper seeks to examine the challenges which patenting of nano-biotechnology entails for the patent regimes of especially TRIPS agreement and how these could be addressed. The paper finally arrives at certain recommendations, to help reconcile the need to incentivize innovation in the new technology, with the imperative of ensuring that the public interest is served and access to the patented knowledge is not hindered.
\end{abstract}

Keywords: Nanobiotechnology, Intellectual Property, TRIPS Agreement, Challenges of patentability.

Introduction
$\quad$ Nanotechnology is a novel and revolutionary branch of technology, where reduction in size has demonstrated magnificent results. Intersection with the field of biotechnology has given rise to nanobiotechnology. Involvement of living forms and the potential to meet human necessities have raised issues that are unique to nanobiotechnology. Nanobiotechnology has been defined in several ways, for example as "an interdisciplinary field of research and development that integrates engineering, physical sciences, and biology through the development of very small physical and biological devices using biomimetically inspired nanofabrication techniques (Daneshyar et al., 2006). While biotech's raw materials are biological, nano-scale technologies involve the manipulation of both living and non-living materials, sometimes in combination. When this is the case, the discipline is known as nanobiotechnology.

In case of nano-biotechnology, the novelty of technology is substantially derived from the reduction in size. The foremost ambiguity is lack of a universal definition of nano-biotechnology. The word "nano" encompasses inventions of $100 \mathrm{~nm}$ in size or smaller. The pharmaceutical industry-likely to be the biggest beneficiary sector from nanobiotechnology-aided research-is based on drug targeting. Nanoparticle efficacy or accuracy of methods using nanoparticles for drug delivery is significantly governed by particle size, which may vary, as different drugs are effective with different particle size. Therefore, fixing a size limit of $100 \mathrm{~nm}$ may rule out the patenting of such particles under the "nano" regime (Hosseini et al., 2011; Daneshyar et al., 2006).

Further, some applications of nanomedicine include nano syringes for drug release and injection of the substance in the cell. Nano-engineered prosthetics enhance the biocompatibility of artificial bones. Nano detectors detect slightest signals associated with malignancy. Nanovectors can carry chemotherapeutic drugs to tumor sites. nanocrystals can be tagged to proteins/DNA for their identification and localization in pathways. nanochips can control delivery of drug dosage. Nano carriers can be used in gene therapy. Nanopore sequencing can be employed in the detection of single nucleotide polymorphism and the diagnosis of pathogens. Nanoimplants can replace damaged sensory organs. As described earlier, in order to be classified as "nano", the size has to be less than $100 \mathrm{~nm}$. In the field of nanomedicine, sometimes a better efficacy is obtained with a molecule larger than $100 \mathrm{~nm}$ but less than 1000 $\mathrm{nm}$ (mathematically, 1 micron $=1000 \mathrm{~nm}$ ). In such situations, it becomes challenging to classify them as nano pharmaceuticals. nanoparticles, due to their small particle size and proportional increase in surface area, enhance the solubility in blood and bioavailability, thereby abating the need for adjuvant or co-solvents and reducing the dosage. The presence of nanoparticles prevents biochemical reactions of the drug. Additionally, the exposure time to the drug is also prolonged. Innovation in nanomedicine mainly focuses on the delivery methods that make use of the above-described inherent properties of nanoparticles or nano carriers. This improves the administration of drugs. It is speculated that established players in the pharmaceutical sector would make use of these nano-based novel drug delivery systems in conjunction with drugs whose patents have expired, thereby introducing new products. Such acts would restrict the entry of generic players in the market (Johnston et al., 2007; Ameden et al., 2005).

A nanostructured material used inside the body as a bone replacement is one of the other example of nanobiotechnology, but so is a hybrid organism created from living and non-living materials, such as the nanoscale 
silicon and muscle-tissue hybrid announced by researchers in early 2005. Nano-biotechnology encompasses a wide range of applications on the molecular scale at the interface between the chemical, physical, and biological sciences (Hosseini et al., 2011; Daneshyar et al., 2006).

Advances in nanomedicine will in the nearby future be able to increase the quality of life and promote full integration in society of people suffering from certain medical conditions, and have therefore an enormous potential. The advances provided by nanotechnology have significantly improved the ability to detect and diagnose disease by introducing small, highly sensitive, inexpensive devices for the manipulation and analysis of cells. Novel nanomaterials and surface modification methods have improved existing techniques that enable scientists to observe and analysis the intracellular operations in real time. Such improvement in the study of cellular functions is helping researchers to detect and study diseases at a very early stage, and will prove instrumental to find suitable cures. An example of one of the most advanced applications of nanobiotechnology is the use of quantum dots for imaging (visualize alterations in human organs or tissue) or the use of carbon nanotube-based glucose sensors to monitor diabetes and other diseases, since they change infrared fluorescence according to the glucose level. Miniaturized subcutaneous chips continuously monitoring key body parameters including pulse, temperature and blood glucose could be implanted in patients or even healthy persons in order to achieve early diagnosis. Implantable sensors can also interface with devices that administer treatments automatically if needed, e.g. drug dispense systems. Many of the technologies being developed in the present blur the line between non-patentable methods for treatment and diagnostic practiced on the human body on one side and patentable products (substances or compositions) and apparatus used in such activities on the other. Some of this important developments in diagnostics and treatment operate totally in vitro, others entirely in vivo, some have a combination of phases in vitro and in vivo, posing patentability questions concerning the patentability exception for Methods for treatment and diagnostic (Hosseini et al., 2011; Daneshyar et al., 2006).

Briefly, rapid technological advances and commercialization of the emerging field of nanobiotechnology will challenge traditional international and domestic regulatory regimes, including intellectual property rights. This article examines the role of the World Trade Organization's Trade-Related Intellectual Property Rights Agreement as a global regulatory device for nanobiotechnology, and questions the applicability of the Agreement with respect to current and future nanobiotechnology applications. With the commercialization of nanobiotechnology already occurring, exploration of the international intellectual property and nanobiotechnology interface is timely (Daneshyar et al., 2006).

Nanobiotechnology patents and TRIPS Agreement

Over the past two decades, the role of intellectual property in all areas of science and technology has exploded globally-primarily due to rules prescribed by the World Trade Organization's TRIPS and by bilateral/regional trade agreements. The TRIPS agreement obligates all WTO member countries to adopt and enforce minimum standards of intellectual property. The TRIPS Agreement requires member countries to make patents available for inventions, whether products or processes, in all fields of technology without discrimination, subject to the standard patent criteria (novelty, inventiveness, and industrial applicability). However, during the negotiations on the TRIPS Agreement, consensus was not reached on the controversial area of biotechnological inventions. The United States and some other developed countries pushed for no exclusions to patentability, while some developing country members preferred to exclude all biological diversity-related inventions from IP laws. For many developing countries, the patenting of life forms and exclusive monopoly protection on biological products and processes that originate in developing countries (or that are based on traditional knowledge) continues to be controversial. Based on some documents, it is states that plants and animals as well as essentially biological processes may be excluded from patentability. However, WTO members must offer protection for plant varieties either by patents and/or by an effective sui generis system. The controversy and debate surrounding the patentability of biotechnological inventions at WTO is relevant to a discussion on nano-biotechnology patents because nanobio scale materials and processes inventions that claim living matter-raise many of the same fundamental questions (nanobiotech patents). Broad nanobiotech patents are already being granted that span multiple industry sectors and include sweeping claims on building blocks of the entire natural world. Should exclusive monopoly patents be granted on the fundamental building blocks of nature? Does the TRIPS Agreement obligate all developing countries to recognize and enforce patents on nanobiotechnology inventions, even those that incorporate plants and animals as well as essentially biological processes? Will overly broad patents or 'patent thickets' on emerging nanobio scale materials, processes and devices prevent researchers in the global South from participating in the nanobiotech revolution? Over the past decade, some governments, the UN Human Rights Commission as well as civil society and social movements have warned of the inequities of IP for the global South. Recently, even at WIPO-the UN body whose mission is to promote and protect intellectual property - the uneven IP playing field and the negative impacts of TRIPS have become untenable for many 
developing nations (Ameden et al., 2005; Bastani \& Fernandez, 2002; Ho, 2001; Thumm, 1998).

Classification of nano-biotechnology inventions

USPTO has classified nanotechnology in class 977 under 35 USC §8 (Classification of Patents) whereas the European Patent Office (EPO) has carved out a Y01N tag for nanotechnology. Under the International Patent Classification, nanotechnology is placed under B82B class. Unlike the nano classifications developed in EU and US patent regime, the absence of a nanobiotechnology patent classification system in some countries makes patent landscaping cumbersome and patents may be issued without divulging the invention area as "nano-biotechnology". This affects future patents in the field.

Further, such challenges increase the onus on the examiner considering the patent applications: the dearth of skilled, aptly qualified, and trained examiners may result in the granting of poor quality patents. Because few individuals have an in-depth and complete knowledge of nano-biotechnology, patent examiners may not have the tools necessary to understand the complexities of the field. This problem can be circumvented by the generation of human resource and labor in this emerging area of technology (Thumm, 1998; Lovgren, 2005).

Patentability Criteria

In order for a patent to be granted, under the national patent laws, it has to refer to an invention that further fulfils the three criteria of novelty, inventive step, and industrial application. Prior knowledge is known as the state of the art and novelty requires that the invention is not part of what is considered to be the state of the art in its field. Concerning the inventive step the invention must neither follow logically from what is already known nor be obvious to a person skilled in the art. The industrial application requirement means that the invention is only patentable if is susceptible of being applicable in any type of industry, including agriculture.

Nano-biotechnology inventions are problematic in two ways. Firstly, they are anticipated by prior art - they are thus not considered as novel due to the pre-existing technologies from which these are believed to derive. For example, traditional medicines (such as ayurvedic preparations, which make use of nanoparticles) are believed to be present in the public domain. Secondly, they fail to meet the threshold of inventive step and can be rendered non-obvious based on being a consequence of mere reduction in size.

The second criterion that the patent application is required to meet involves non-obviousness or inventive step. Non-obviousness is more crucial and likely to pose obstacles in patenting for nanobiotechnology in general. The first case that raised the question of non-obviousness with respect to nanotechnology is that of In re Kumar, where the Board had held the claimed invention of "aluminium oxide particles" as unpatentable because it was obvious in view of a prior patent (the Rostoker
Patent). The Board opined that there was an overlap between the particle range of Rostoker patent $(5-15 \mathrm{~nm})$ and Kumar's patent $(4-16 \mathrm{~nm})$. The petition was vacated.

The third criterion for patentability is whether the subject is "capable of industrial application "It may initially seem that this criterion would pose no problems for the patenting of nanobiotechnology inventions. On analysis, however, it is clear that utility is very crucial for nanobiotechnology-based inventions. Nanobiotechnology falls under the class of "unpredictable" arts like biotechnology - one of its predecessors. There is the possibility of huge variation in the laboratory results and actual results when technology such as nanobiotechnology is put to use. In the laboratory stage, it is not possible to determine the possible impact of external factors on products born out of a technology. Inoperability of such products may render them nonpatentable, as they would fail to comply with the utility requirements (Thumm, 1998; Lovgren, 2005).

\section{Distinction between discoveries and inventions}

In the case of the inventions in the field of nanobiotechnology, naturally occurring substances, microorganisms or other biological materials face special problems. One such basic theoretical issue relates to the concept of invention and discovery. In identifying what is an invention and what is not, for providing intellectual property protection, it is usual to distinguish an invention and discovery. The patent laws of most of the countries exclude discoveries from patent protection. However, if the subject-matter concerns a process that was developed in order to enable a substance found in nature to be isolated and obtained from its surroundings, such process may be patentable. Thus, the distinction should be taken into consideration when patenting nanobiotechnology inventions.

The problem with respect to nano-biotechnological patenting is, to what extent the traditional concept of invention covers inventions in the field of nanobiotechnology for intellectual property protection? As mentioned above, Nanobiotechnology designates a group of techniques that enable the manipulation of biomatter at nanoscale, which means building structures and new materials at an atomic, molecular and macromolecular scale. The common definition of discovery includes the products of nature because invention in the field of nanobiotechnology, directly or indirectly, relates to the living forms, which are products of nature. Hence, the distinction between inventions for which protection is available and discoveries, which cannot be protected, seems a problem for nano-biotechnological products. The issue of inventiveness of discovery gets a new dimension when it comes to patenting living subject matter. It is always an issue because most of the nanobiotechnological inventions amount to the identification of naturally occurring living materials.

Based on the $27^{\text {th }}$ Article of the TRIPS Agreement indicates that the emerging field of nanobiotechnology 
falls within the scope of patentable subject matter within international IPRs. While the TRIPS Agreement does not pose any significant challenges to the patenting of current nanobiotechnology applications, the blurring of the invention/discovery interface and the probable convergence of nanotechnology and biotechnology in the medium term may challenge the current IPRs regime (Hosseini et al., 2011).

Importantly however, not all nanobiotechnology applications may be protected by patent grants. As provided for by Article 27(1), patents shall be available for any invention and not mere discoveries. While the TRIPS Agreement fails to provide a definition of 'invention,' it would appear that Article $27(1)$ is an attempt to discriminate between rapidly blurring distinctions of 'inventions' and 'discoveries.' As compounds are naturally occurring, Article 27(1) technically prohibits the patenting of the compounds themselves. Article 27(1) does enable however that a requisite inventive step be deemed to belong to the process of creation, rather than the creation itself (Hosseini et al., 2011). Bastani and Fernandez, noted that the development of innovative technologies including nanotechnology has resulted in a blurring of the interface that previously existed between discoveries and inventions. The blurring of this distinction can be best illustrated by examining the patentability debate of 'patents on life' within the nanobiotechnology industry (Bastani and Fernandez, 2002).

In a critique of nanobiotechnology patents under the framework of the TRIPS Agreement and the EC Biotechnology Directive, some reports have argued that the indeterminate wording of the Agreements provides scientists and potential patentees with too much flexibility in what they can and cannot patent. These reports also stated that classes of patents based on mere discovery have become 'patentable' despite failing to fulfil the 'invention' criteria. These include the discovery of human cells such as umbilical cord cells, plant genes including rice genome sequencing and therapeutic cloning and stem cell isolation procedures. This argument lends itself to the interpretation that the processes leading to such 'discoveries' fall outside the spirit of the TRIPS Agreement, and should not be patentable (Ho, 2001).

However, there is a timely opportunity for governments and society to consider whether it is prudent to provide the opportunity for monopolisation over these basic compounds and structures, while bearing in mind the future consequences of patenting within the realm of nanobiotechnology. In the longer term, the convergence of nanotechnology and biotechnology may require policy makers to explore the utility of a sui generis patent regime for nanobiotechnology. The creation of a specialized patent like system would not be without precedent sitting along side the Plant Breeders' Rights regime and would acknowledge the inherently distinct nature and characteristics of manipulating living organisms with atomic precision. This option could present a middle ground between the current international IPRs framework provided by the TRIPS Agreement, while encouraging innovation without undermining the broader objectives promised by nanobiotechnology (Lovgren, 2005; Mukesh et al., 2006).

\section{Patentability Exclusions in Nanobiotechnology}

Patent rights in particular can only be granted to inventions. Patent law excludes from patentability any object that cannot be considered an invention. The protection of the public interest, i.e. general values and interests of the community, is one of the traditional functions of the state. Thus, States have the sovereign right to protect the public interest, such underlines all legislative activity and patent law is not an exception to this general principle. The TRIPS agreement has excluded certain inventions from the ambit of patentability. These exceptions are in nature different from subject matters excluded from patentability previously analyzed above. Exceptions to patentability concern inventions who may fulfill all patentability criteria (novelty, inventive step, industrial application) and still can not be granted patent protection since those inventions should not be subject to commercial exploitation, while the former relates to subject matter that due to its nature (or lack of technical nature) can not be the object of a patent right. The notions of order public (public order), and morality are not defined in the agreement. However, it is clear that those inventions that cause injury to human, animal and plant life as well as the environment are excluded. Member countries are given flexibility to adjudicate such matters. Some countries may still provide patent protection for inventions that cause damage to the environment. Patenting of genetically engineered organisms and life forms is generally possible under these provisions. Further, it is also possible for a state to provide patent protection to a gene or a whole organism (Kamariah et al., 2012; Altbach, 2007; Audretsch and Aldridge, 2006).

Some decisions by the European Patent Office (EPO) show that the effects of an invention on the environment may constitute a valid ground for denying patentability. However, the EPO refused to assume a regulatory role on the introduction of genetic engineering inventions. In dealing with this issue, one of the opposition decisions argued that: "A patent does not give a positive right to its proprietor to use the invention but rather only confers the right to exclude others from using the invention for a limited period of time. If the legislator is of the opinion that certain technical knowledge should be used under limited conditions only it is up to him to enact appropriate legislation." As noted by some reports, patent examiners "are not specifically trained in ethics or in risk assessment. Since patents do not give a positive right to use the protected inventions, other bodies have to shoulder the responsibility for the decisions of society whether certain technology can and should be put into practice." 
Although certain kinds of inventions have been excluded from the patentability but patenting of microorganisms (nano microorganisms) and nonbiological processes is allowed in TRIPS. Therefore, in other words, microorganisms (nano microorganisms) per se, process of their production and process of their use are made patentable, TRIPS agreement however, neither defines the term "microorganism" nor does it specify any parameters concerning the scope of protection to microorganism such as microorganism per se, whether found in nature or created artificially such as genetically modified organism (GMO) etc. However, the EC directives on microorganisms define it as "any micro biological entity, cellular, or non cellular, capable of replication or transferring genetic material. EC directives have also defined "biological material" as any material containing genetic information and capable of reproducing itself or being reproduced in a biological system (Agrawal, 2001; Australian Research Council, 2000; Bjerregaard, 2010).

Challenges of patenting Nano-biotechnology Inventions

Nanobiotechnology can to be analyzed in the light of environmental jurisprudence across various jurisdictions. For example a right to life under countries' constitutions. This right is very broad and capable of imbibing various related rights including the right to live in a healthy and wholesome environment as has been laid in a series of cases. The "polluter pays" principle and the "precautionary" principles governing the environment have been judicially recognized in the form of precedent for future issues arising from conflicts between the environmental implications of technologies such as nanobiotechnology and the right to a healthy environment. The high permeation ability of nanoparticles in the bodies of humans and animals can result in environmental damage is caused by nanobiotechnology than any other known technologies (nanotoxicology).

As an instance, the case of Plant Genetic Systems/Glutamine Synthetase Inhibitors involved an invention where genetic engineering was applied to plants to render them herbicide resistant. It was held that the unchecked use of technology to alter natural traits, which caused prejudice to other living organisms and adversely affected the environment, was not patentable. In addition, there are some other challenges in nanobiotechnology.

Experiments have been carried out that could never have been done in classical breeding and that have not been seen in evolution. In classical breeding close relatives can be crossed. Occasionally genes can cross biological boundaries with viruses and bacteria but not on this scale. Now we have a technology revolution that allows scientists and companies to bypass every single biological boundary in the plant and animal kingdoms. That is why it is both exciting from an investment perspective and terrifying from a social, cultural, and environmental perspective. It is now possible to both customize and mass-produce identical copies of an original living being with the same quality controls and design principles that were used on the assembly line with the chemical products in the twentieth century. Over the next few years, the term 'genetic pollution' will be much in use. Genetic pollution is very different from chemical pollution. Genetically modified organisms (GMOs) are alive, so they are more unpredictable when you place them in the environment. They reproduce, for instance. Chemicals do not reproduce. GMOs mutate, they proliferate, and they migrate (Bjerregaard, 2010; Powers and McDougall, 2005; Patent Act, 1952).

Genetic discrimination is going to loom as significantly in the future as gender discrimination or ethnic and racial discrimination has in the past. However, what are the consequences of reducing the entire gene pool to intellectual property owned by a handful of life-science companies? What are the implications of genetically programming traits into sperms, egg, and embryo before conception or after conception, and of growing up in a world where people are discriminated against because of their genotype or their genetic profile? What are the consequences of making human baby by design principles? Whether the artificial creation of cloned creatures en masse will mean the end of nature and the substitution of a laboratory -conceived second genesis. Will the mass release of thousands of genetically modified organisms mean spreading genetic pollution across our biosphere and irreducible damage to our environment?

Who is going to control all this? The human genome has been mapped and now the rush is on to locate every one of those genes and then to secure intellectual property rights over then. If this goes unchallenged, in less than ten years a handful of life-science companies will own the genetic blueprints of our species. There is a North/South issue here. A gene cannot be created in the laboratory; it is not an extractive industry and many of the genetic resources are in the Southern hemisphere. Companies are looking for rare genes and microbes, plants, animals and humans-indigenous populations- to claim them as property. If we allow the great gene pool to be enclosed as either political property owned by governments or intellectual property owned by commercial companies, it is guaranteed that there will be gene wars in the future (Roberts and Malone, 1996).

In the new era, markets are making way for networks, and ownership is steadily being replaced by access. This does not mean property disappears in the coming Age of Access. Quite the contrary. Property continues to exist but is far less likely to be exchanged in markets. Instead, suppliers hold on to property in the new economy and lease, rent, or charge an admission fee, subscription, or membership dues for its short-term use. Our materials base is shifting from fossil fuels, metals, and minerals the raw resources of the industrial revolution to genes the raw resources of the biotech century. 
In the Industrial Age, nonrenewable resources fossil fuels, chemicals, metals, and minerals were transformed into pure commodities. They were exhumed, extracted, processed, and sold by weight and grade in the commodities market. They were treated, from beginning to end, as negotiable property whose ownership could be transferred from sellers to buyers at each step of the economic process. Genes are not, however, treated the same way. They are not sold but only licensed out; not bought, only leased. Genes remain the possession of the suppliers in the form of patents and are loaned to users for short durations.

When chemists discovered new chemical elements in nature in the last century, they were allowed to patent the processes they invented to extract and purify the substances but were not allowed to patent the chemical elements themselves. Patent laws in the United States and in other countries prohibit discoveries of nature from being considered inventions. In 1987, however, in apparent violation of its own statutes governing patents on discoveries of nature, the PTO issued a sweeping policy decree declaring that the components of living creatures genes, chromosomes, cells, and tissues are patentable and can be treated as the intellectual property of whoever first isolates their properties, describes their functions, and finds useful applications for them in the marketplace. The transnational life-science companies have been quietly buying up the remaining independently owned seed companies in recent years, giving them vast control over the germ plasm upon which all of agricultural production depends. By patenting the world's remaining seed stock, life-science companies are effectively gaining control over much of the agricultural production of the planet. They are the suppliers, and every farmer in the world becomes a user, buying access to the seeds of life each new growing season. Farmers and scientists who purchased animals in the past have always been able to claim their offspring as their property. That is no longer the case. Technically, the supplier of patented animals owns all the offspring of the same genotype. Therefore if an animal is cloned and patented, the cloned copies are considered the intellectual property of the patent holder, and a royalty must be paid for each birth (RMC, 2011; Slaughter and Rhoades, 2004).

Conclusion

Nano-biotechnology has achieved remarkable success in research and development, innovation, legal protection and commercialization in western countries. Legislation and regulations are in place to assess risk, comply with safety measures, and regulate the outcomes of such research. With a promise of widespread application, nanobiotechnology research is still at an early stage of development in world. This technology raises issues, which are in conflict with intellectual property rights protection and non-commercial laws (such as the environmental laws or privacy rights). In the absence of consonant patent law provisions, nanobiotechnology will encounter challenges with respect to the criteria of novelty, inventive step, being capable of industrial application.

As the next 'technological revolution', nanobiotechnology will be a key technology for economic development in the twenty-first century. Consequently, a review of the current international patent framework for this emerging technology is crucial. Importantly however, not all nanobiotechnology applications may be protected by patent grants. When considering the range of nanobiotechnology products that may be patentable under the current it international framework, distinctions will need to be drawn between inventions and discoveries, products and processes. The use of eco marks on nano-biotechnology products are proposed to ensure environmental safety and consonance. This would further help in dealing with the proposed obstacles to nanobiotechnology products Since patent law is technology-specific, providing guidelines to examiners for assessment of patent applications is a good practice and should be encouraged as it would aid in the issuing of better quality nanobiotechnology patents. Documentation and consolidation of scattered prior art in the form of a database is necessitated. Ethics should be given weight in relation to ignorance. Nano ethics committees or the inclusion of nano ethics under the present bioethics committee should be considered as inventions that may be rendered non-patentable in India on ethical and moral grounds. The emergence of recent concepts such as access to knowledge (A2K) propounds accessibility of knowledge to all based on justice and equity. Such contentions raise a voice against the monopolistic character of patent rights. This gives birth to the most acute dilemma, which strikes at the very root of the patent law jurisprudence. It remains to be seen what impact such movements will have on emerging technologies such as nanobiotechnology under the Intellectual Property regime and should be studied .The early recognition of these concerns should enable policy makers and governments to contemplate the future applications of nanobiotechnology and tailor the international IP framework accordingly. These issues should provide policy makers and government with the opportunity to implement a comprehensive and effective system to regulate international IPRs within nanobiotechnology. In doing so countries must recognize the imperative to balance the needs of commercial investors and innovation against the broader objectives and utopian ideals promised by nanobiotechnology. Indeed, inactivity of policy makers and government now is likely to result in commercial uncertainty in the future.

\section{References}

1. Agrawal A (2001) University-to-Industry Knowledge Transfer: Literature Review and Unanswered Questions. Int. J. Manage. Rev.3, 285-302. 
2. Altbach PG (2007) Peripheries and Centres: Research Universities in Developing Countries. Higher Educ. Manage. Policy. 19, 106-130.

3. Ameden H, Qaim M and Zilberman D (2005) Adoption of Biotechnology in Developing Countries. Springer Publisher.

4. Audretsch DB and Aldridge OA (2006) The knowledge Filter and Economic Growth: The Role of Scientist Entrepreneurship. Ewing Marion Kauffman Foundation.

5. Australian Research Council (2000) Research in the National Interest; Commercializing University Research in Australia, Australian Research Council, Canberra.

6. Bastani B and Fernandez D (2002) Intellectual property rights in nanotechnology, Menlo Park, CA; Fernandez \& Associates, LLP, Available at: http://www.iploft.com/Nanotechnology.pdf.

7. Bjerregaard T (2010) Industry and Academia in Convergence: Micro-Institutional Dimensions of R\&D Collaborations. Technovation, 30, 100-108.

8. Daneshyar SA, Kohli K and Khar RK (2006) Biotechnology and intellectual property. Sci. Res. Essay. 1, 020-025.

9. Ho M (2001) why biotech patents are patently absurd-scientific briefing on TRIPS and related issues. Institute of Science in Society, London.

10. Hosseini SJ, Esmaeeli S and Ansari B (2011) Challenges in commercialization of nano and biotechnologies in agricultural sector of Iran. Afr. J. Biotechnol. 10, 6516-6521.

11. Johnston PD, Santillo J and Parr D (2007) Policy on Nanotechnology. Greenpeace Environmental Trust.

12. Kamariah I, Senin AA, Mun SW, Chen WS and Musibau AA (2012) Decision making process in the commercialization of University patent in Malaysia. Afr. J. Bus. Manage. 6, 681-689.

13. Lovgren S (2005) One-Fifth of Human Genes Have Been Patented, Study Reveals for National Geographic News.

14. Mukesh P, Sridevi B, Manoj KRE and Anuradha BS (2006) Internet: A place for patent retrieval. Afr. J. Biotechnol. 5, 786-792.

15. Patent Act (1952) The US Patent and Trademark Office.

16. RMC (2011) Retrieved on the 23rd September 2011 from www.rmc.utm.my, this is the official website of the Research Management Centre of Universiti Teknologi Malaysia.

17. Powers JB and McDougall PP (2005) University Start-up Formation and Technology Licensing with Firms that go Public; A Resource-Based View of Academic Entrepreneurship. J. Bus. Ven. 20, 343358.

18. Roberts EB and Malone R (1996) Policies and Structures for Spinning of New Companies from
Vol. 5 No. S3 (Mar 2012)

ISSN: 0974- 6846

Research and Development Organizations R\&D Manage.15, 283-298.

19. Slaughter S and Rhoades G (2004) Academic Capitalism and the New Economy: Markets, State and Higher Education. Baltimore: JOHN Hopkins University Press.

20. Thumm N (1998) Recent developments with intellectual property rights protection for biotechnological inventions-a reflection on Spain. In: Paper presented to the PATLIB98, Alicante European Patent Office. 